\title{
Seasonal Variation in Month of Diagnosis of Polish Children with Type 1 Diabetes - A Multicenter Study
}

\section{Authors}

Agnieszka Szypowska1, Anna Ramotowska1, Marta Wysocka-Mincewicz², Artur Mazur', Lucyna Lisowicz', Iwona Beń-Skowronek ${ }^{5}$, Joanna Sieniawska ${ }^{5}$, Bożenna Klonowska ${ }^{6}$, Dorota Charemska ${ }^{6}$, Jolanta Nawrotek ${ }^{7}$,

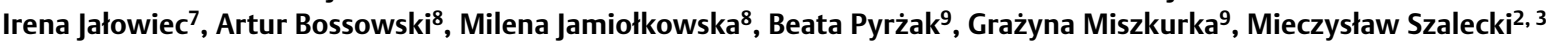

\section{Affiliations}

1 Department of Paediatrics, Medical University of Warsaw, Poland

2 Department of Endocrinology and Diabetology, Children's Memorial Health Institute, Warsaw, Poland

3 Faculty of Medicine and Health Sciences, UJK, Kielce Poland

4 II Department of Paediatrics, Paediatric Endocrinology and Diabetes, Medical Faculty University of Rzeszow, Poland

5 Department of Paediatric Endocrinology and Diabetology, Medical University of Lublin, Poland

6 Department of Clinical Pediatrics. Faculty of Medical Sciences, University of Warmia and Mazury in Olsztyn, Provincial Specialist Children's Hospital, Olsztyn, Poland

7 Endocrinology and Diabetology Ward, General District Hospital, Kielce, Poland

8 Department of Pediatrics, Endocrinology, Diabetology with a Cardiology Division, Medical University in Białystok, Poland

9 Department of Pediatrics and Endocrinology, Medical University of Warsaw, Poland

Key words

seasonality, childhood, recognition, diabetes type 1

$\begin{array}{ll}\text { received } & 03.10 .2017 \\ \text { revised } & 12.12 .2017 \\ \text { accepted } & 21.12 .2017\end{array}$

Bibliography

DOI https://doi.org/10.1055/s-0043-125321

Published online: 5.3.2018

Exp Clin Endocrinol Diabetes 2019; 127: 331-335

(c) J. A. Barth Verlag in Georg Thieme Verlag KG Stuttgart .

New York

ISSN 0947-7349
Correspondence

Agnieszka Szypowska

Department of Pediatrics

Medical University of Warsaw

Żwirki i Wigury 63A, Warsaw

Poland

Tel.: +48/22/3179 425, Fax: +48/22/3179425

agnieszka.szypowska@gmail.com

\section{ABSTRACT}

Aim The seasonal variation of incidence of type 1 diabetes (T1D) theory supports the hypothesis that environmental factors play a role in the onset of the disease. The aim of this study is to assess seasonality of month of diagnosis in children with T1D in Poland.

Material and methods the study group consisted of 2174 children from eastern and central Poland diagnosed with T1D between 2010 and 2014. Analysis was performed in different age groups, based on place of residence (rural/urban area) and depending on sex.

Results We noted significant seasonality in the incidence of T1D with a peak in diagnosis of diabetes in January and the minimum rate in June. A total of 423 (19\%) children were diagnosed in the warmest months (June to August with a mean temperature of $16.8^{\circ} \mathrm{C}$ ) compared to $636(29 \%)$ recognised in the coldest months (December to February with a mean temperature of $-1.6^{\circ} \mathrm{C}$ ), OR $0.5795 \% \mathrm{Cl}$ [0.51-0.67], $\mathrm{p}<0.0001$. We noted a more flat seasonal pattern in children $0-4$ years of age compared with subjects 5-17 years old with a week correlation of trend comparison between both groups, $r=0.69$, $p=0.001$. Similar seasonal variation in the incidence of T1D was noted in children from urban and rural setting. For girls, seasonal pattern peaks were observed one month earlier as compared to boys.

Conclusions Seasonal variation in incidence of T1D diagnosis of Polish children supports the role of different environmental factors in diabetes onset. The majority of children were diagnosed with diabetes in autumn and winter. 


\section{Introduction}

Genetic as well as environmental factors affecting the immune system have been implicated in the pathogenesis of type 1 diabetes (T1D). An interplay between genetic and environmental triggers results in a varying frequency of incidence rates between various populations. It has been suggested that such environmental factors as infections and vitamin D levels may influence the seasonality of T1D [1].

Among several viruses, enteroviral infections, especially those caused by coxackievirus B, have been linked to the development of T1D. Krogvold et al. provide evidence for the presence of enterovirus in pancreatic islets of newly recognized T1D patients [2]. The authors conclude that there is a possibility that a low-grade enteroviral infection in the pancreatic islets contributes to T1D progression. Further studies show that antibodies against the group B 1 coxackieviruses are more frequent among diabetic children as compared to a control $[3,4]$. Coxsackievirus B was the most frequently isolated serotype (30\%) among 116 isolations of enteroviruses performed in Polish population [5].

In the temperate climate regions of Poland the greatest number of enteroviral infections occur during the summer and early autumn months. The tropical and subtropical areas of Poland maintain a constant level of enteroviral infections throughout the year [6]. Since viral infections and vitamin D level [7] demonstrate seasonal fluctuations, some studies have tested the hypothesis that the diagnosis of diabetes may also display seasonality patterns. The seasonality pattern seems to be dependent on geographical position [8]. However, the results are conflicted as only 42 of 105 centers collected by the World Health Organization Diabetes Mondiale Project over the period 1990-1999 reported seasonality in the incidence of T1D. A different pattern was reported by two out of the four centres with significant seasonality in the southern hemisphere [8]. Seasonality at the clinical diagnosis of T1D was noted in European countries with the highest percentage of incident cases in January and the lowest in June. Similar seasonality patterns were noted in different age-groups, females and males. The pattern differed by the year of manifestation [9].

The aim of the current study was to investigate the seasonality of T1D recognition in different age groups of children living in the eastern and central regions of Poland.

\section{Material and methods}

We included data of all children and adolescents with newly recognised T1D admitted between January 2010 and December 2014 to seven diabetes/endocrinology departments of hospitals distributed across the following Polish regions: Podkarpackie, WarmińskoMazurskie, Lubelskie, Świętokrzyskie, Podlaskie and Mazowieckie. These regions are situated in eastern and central Poland. Depending on the hospital, data regarding birth and diabetes recognition were collected retrospectively from paper or electronic documentation or prospectively from electronic databases. Type 1 diabetes in children was diagnosed according to International Society for Paediatric and Adolescent Diabetes criteria [10].
We assessed in all children seasonality in the incidence of T1D. Additional comparison between autumn to winter months (from September to February) and spring to summer months (from March to August) was conducted, and OR was calculated in reference to months with lower incidence. Moreover, the difference in diabetes incidence between the warmest and the coldest months was evaluable. Meteorological data regarding temperature was provided by the Polish Institute of Meteorology and Water Management.

Due to the higher incidence of diabetes among younger children in Poland, and possibly other seasonal patterns in different ages, patients were divided into two age groups: $0-4$ and 5-17 years. Additional analysis was performed based on place of residence (rural/urban area) and depending on sex.

The study protocol was approved by the Ethics Committee of the Medical University of Warsaw.

\section{Statistical analysis}

Analysis of time series data was performed using a statistical $R$ package. We used R project for Satistical Computing version 3.3.1, with package forecast version 7.1 and package TTR version 0.23 1. To estimate trend and seasonal components of a seasonal time series classical seasonal decomposition (Census Method 1) was used, as the best fit to the data. In the model a seasonal time series consists of a trend component, a seasonal component and an irregular component. The seasonal component is computed as the average for each point in the season. The medial average of a set of values is the mean after the smallest and largest values are excluded. The resulting values represent the (average) seasonal component of the series. The original series were adjusted by subtracting from it, the seasonal component. Trend component is different from the seasonal component in that it is usually longer than one season, and different cycles can be of different lengths. The random or irregular (error) component were isolated by subtracting from the seasonally adjusted series the trend component. Comparisons of groups were performed by chi-square test and analyses of trends were tested using Pearson correlation in Statistica 6.0. Pearson correlation coefficient analysis was done for comparing the two time series for groups of boys and girls, or rural and urban place of residency. In this analysis the pattern of curves, not the group data, were compared. A high correlation between two patterns from different groups indicates that these patterns are likely similar, but maybe on a different level. The Odds Ratio (OR) was calculated with $95 \%$ confidence intervals $(\mathrm{Cl})$. P-values less than 0.05 were considered as significant.

\section{Results}

The study group consisted of 2174 children (1007 girls) with a mean age of $9.3 \pm 4.5$ years. The characteristic of the study population is shown in $>$ Table 1 . We noted significant seasonality in the incidence of T1D. The estimated seasonal factors are given for the months January-December in $>$ Table 2 . The largest seasonal factor is for January (about 15) and the lowest is for June (about -14), indicating that there seems to be a peak in diagnosis of diabetes in January and a minimum rate in June. In the model a seasonal time 
series consists of a trend component, a seasonal component, and an irregular component (random). - Fig. 1 shows the original time series (top), the estimated trend component (second from top), the estimated seasonal component (third from top), and the random component (bottom). The estimated trend component shows a very intensive increase at the end of 2012 and then some constancy between 2013 and 2014.

A total of $423(19 \%)$ children were diagnosed in the warmest months (June to August with a mean temperature of $16.8^{\circ} \mathrm{C}$ ) compared to 636 (29\%) diagnosed with T1D in the coldest months (December to February with a mean temperature of $-1.6^{\circ} \mathrm{C}$ ), OR 0.57 $95 \% \mathrm{Cl}[0.51-0.67], \mathrm{p}<0.0001$. T1D onset was noted more frequently in autumn-winter than in spring-summer: 1270 (58\%) vs. 904 (42\%) cases, respectively, OR $1.9795 \% \mathrm{Cl}$ [1.75-2.22], $\mathrm{p}<0.0001$ (> Fig. 2).

There were 476 children aged $0-4$ years ( 241 girls) with a mean age of $3.1 \pm 1.2$ years and 1698 children aged $5-17$ years ( 766 girls) with a mean age of $10.9 \pm 3.6$ years. We noted a more flat seasonal pattern in children $0-4$ years of age compared with subjects $5-17$ years of age with a weak correlation trend comparison between both groups, $r=0.69, p=0.001$ ( $\triangleright$ Fig. 3 ).

In the trend comparison in the T1D incidence between girls and boys the correlation was not statistically significant, which means that this trend is different $(r=0.5, p<0.09)$. However we noted that these curves pattern seemed to be "shifted one month" (in the girls group peaks are observed earlier), after adjusting to this observation these curves were similar (strong correlation $r=0.7192$, $\mathrm{p}<0.008$ ) (> Fig. 4).

A total of 1313 children (608 girls) with a mean age of $9.2 \pm 4.5$ lived in an urban area and 861 children (399 girls) with a mean age of $9.3 \pm 4.5$ lived in a rural area. The curve of T1D incidence in the sequenced months of urban children had a very strong correlation in trend comparison, when compared to the rural group $(r=0.8172$, $p<0.001$ ), which means that no difference was observed.

- Table 1 Characteristics of the study population.

\begin{tabular}{|l|c|c|c|c|}
\hline & $\begin{array}{c}\mathbf{0 - 1 7} \\
\text { years }\end{array}$ & $\begin{array}{c}\mathbf{0 - 4} \\
\text { years }\end{array}$ & $\begin{array}{c}\mathbf{5 - 9} \\
\text { years }\end{array}$ & $\begin{array}{c}\text { 10-17 } \\
\text { years }\end{array}$ \\
\hline Number & 2174 & 476 & 689 & 1009 \\
\hline Female/Male & $1007 / 1167$ & $241 / 235$ & $338 / 351$ & $428 / 581$ \\
\hline Age (years) & $9.3 \pm 4.5$ & $3.1 \pm 1.2$ & $7.4 \pm 1.5$ & $13.4 \pm 2.2$ \\
\hline Urban area & 1313 & 287 & 419 & 607 \\
\hline Number & $608 / 705$ & $145 / 142$ & $198 / 221$ & $265 / 342$ \\
\hline Female/Male & $9.2 \pm 4.5$ & $3.1 \pm 1.1$ & $7.5 \pm 1.4$ & $13.3 \pm 2.2$ \\
\hline Age (years) & 861 & 189 & 270 & 402 \\
\hline Rural area & $399 / 462$ & $96 / 93$ & $140 / 130$ & $163 / 239$ \\
\hline Number & $9.3 \pm 4.5$ & $3.2 \pm 1.2$ & $7.4 \pm 1.5$ & $13.4 \pm 2.2$ \\
\hline Female/Male & \multicolumn{5}{|l}{}
\end{tabular}

\section{Discussion}

Our study showed a sinusoidal seasonal pattern in the incidence of T1D with a lower number of children diagnosed in spring-summer and a higher frequency in autumn-winter. Similar to our results other authors confirmed the seasonality in the incidence of T1D [7, 11-17]. However, no significant seasonality was observed in some studies $[7,18,19]$. The seasonal pattern in the diagnosis of T1D in our study showed the highest incidence in January and the lowest in June, which is in accordance with previous reports $[9,20,21]$. In their study, Samuelsson et al. evaluated the seasonal pattern of diagnosis of T1D between 1977-2001 in children in the south-east of Sweden. Due to an increased rate of T1D incidence during the 25 years of follow-up the authors divided the study period into periods of 5 years and it was only during the last two periods that significant seasonal variation occurred [9]. There were no differences in seasonal pattern between four 5 -year periods in European countries during 1989-2008 [12]. In our study it is predicted that the diagnoses of T1D in the coming years will be the highest in January and the lowest in June. Health forecasting seems to be a useful tool for health service in diabetes care planning.

It is speculated that seasonality in diabetes incidence may be caused by some environmental factors such as viral infection. The seasonal pattern in diabetes onset in Japanese children found in 1987 was linked to an epidemic of Coxsackie B3 in 1987 [16]. With the exception of 1987, no seasonal variation in the month of onset was observed in this cohort. It was confirmed that school-aged children are of particular importance for viral infection transmission and temporary school closures are effective intervention to reduce influenza transmission [22]. Although we do not have any data regarding viral epidemics in our regions during the study period, the increase in diabetes onset from September may be linked with the beginning of the school year. As compared to during holidays, children during the school year are more prone to infections, have less activity, higher stress levels and spend less time in the sun, which results in lower levels of vitamin D3. These environmental factors may influence the immune system, decrease insulin sensitivity and accelerate diabetes onset.

The different seasonal pattern in children $0-4$ years of age compared to older subjects may be partly explained by exposure to other environmental factors. In Poland great number of enteroviral infections occur during the summer. Considering that seasonal infections are more common in younger children than in adolescents, we may speculate that some children attend kindergarten also during summer when they are exposed to enteroviral infections. Furthermore, according to TEDDY study, seroconversion occurs in children mainly between 27.7 (15.2-48.3) months of age[23]. One of the possible explanation of the more flat seasonal pattern in children $0-4$ years of age may be obligatory vitamin $D$ supplementation in lactating women and their infants. Additionally, in this age group high aggressive destruction of beta cells is

> Table 2 The estimated seasonal factors given for the months January-December.

\begin{tabular}{|c|c|c|c|c|c|c|c|c|c|c|c|c|}
\hline Month & Jan & Feb & Mar & Apr & May & Jun & Jul & Aug & Sep & Oct & Nov & Dec \\
\hline Factor & 15.03 & 3.80 & 0.63 & -1.59 & -8.95 & -14.01 & -7.46 & $-6,57$ & 3.21 & 13.15 & 2.32 & 0.43 \\
\hline
\end{tabular}




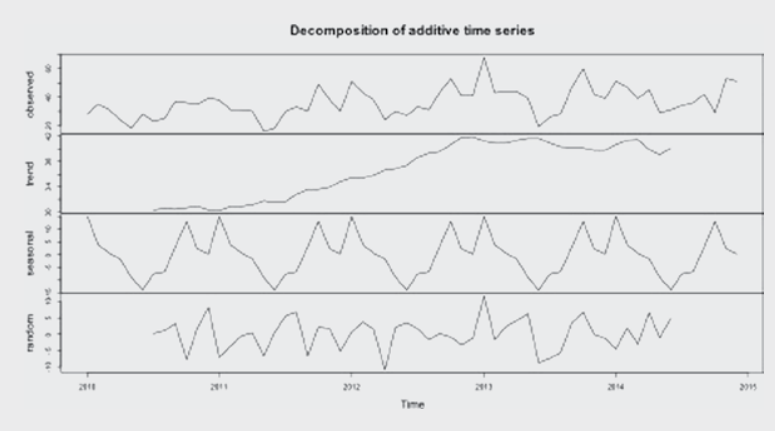

-Fig. 1 Decomposition of seasonal diabetes diagnosis data in an additive model.

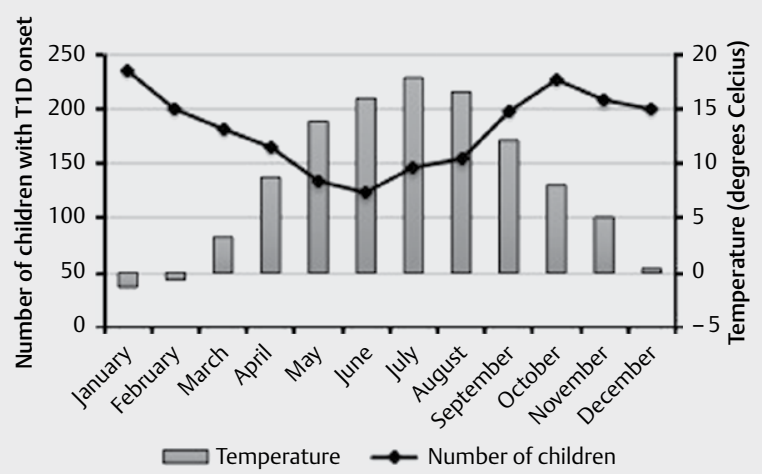

Fig. 2 Relationship between incidence of type 1 diabetes recognition and the mean temperature in different months at diabetes diagnosis.

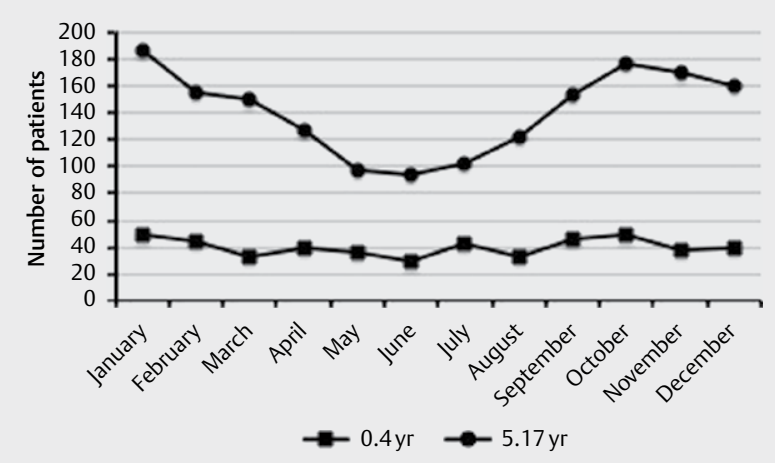

-Fig. 3 Seasonal pattern at diabetes onset in different age groups.

noted which may be less dependent on environmental triggering factors [24]. Some authors demonstrate no seasonal pattern in the $0-4$ years age group [25]. Patterson et al. claim the least seasonal variation in those under 5 years of age as compared to older children registered in 23 European counties during 1989-2008 [12]. In a Greek population, children less than 3 years old had a peak incidence occurring during the warmer months and the older group had peak values occurring during the cold months [10]. Similarly, Rosenbauer et al. report significant seasonal variation in diabetes

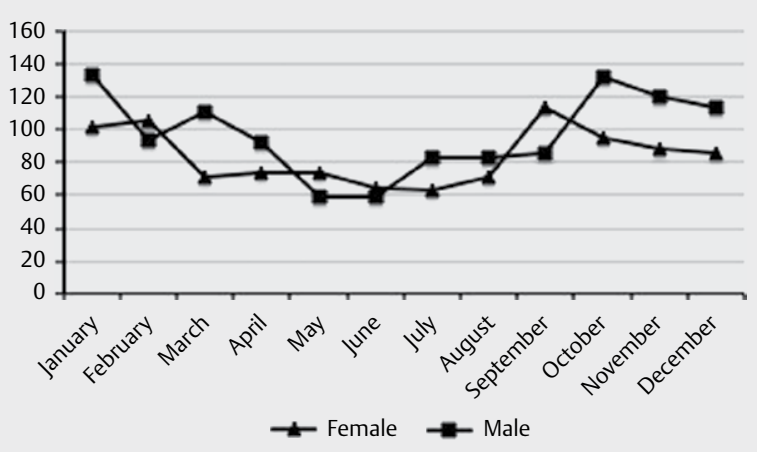

- Fig. 4 Seasonal pattern of type 1 diabetes recognition in female and male.

incidence in German children under 5 years of age with the highest rate during summer (June to August) and the lowest rate in spring (March to May) [26].

The current study showed that in the girls group T1D peaks were observed one month earlier than in boys. The possible explanation of this phenomenon may be more expressed symptoms of yeast vulvitis in girls which may influence more frequent urine analysis compared to boys and in consequence earlier recognition of diabetes. A significant seasonality in the incidence of T1D diagnosis in both genders has been confirmed in other studies [9, 10, 21, 24]. On the other hand, some authors suggestthat a statistically significant seasonal pattern could be confirmed for males, but not for females [27, 28]. Interestingly, Samuelsson et al. report not only seasonal variation of T1D incidence among Swedish children but also seasonal variation of C-peptide at diagnosis [20]. This seasonal variation of C-peptide was significantly correlated to the seasonal variation of diagnosis and was more pronounced in boys than in girls.

Recent studies confirm the role of vitamin $D$ in the incidence of T1D possibly by suppressing immune responses. High-dose vitamin D supplementation early in life protected against T1D [29]. Moreover, vitamin $D$ deficiency in pregnancy may increase the incidence of type 1 diabetes in genetically predisposed subjects [30]. In Poland, vitamin D deficiency affects both children and pregnant women. The main reason for vitamin D deficiency in Poland are climate conditions (with adequate vitamin D synthesis only between April - September) and limitations of skin synthesis due to the use of sun screens, living indoors, or air pollution [31]. We hypothesised that there might be differences in limitations of skin synthesis between children living in urban and rural places that may cause differences in seasonal patterns. Although in our population more children with newly recognised T1D lived in urban than in rural areas we noted similar seasonal variation at diabetes onset in both groups.

The limitation of our study is the short period of observation. Future data is needed to observe if the trend of seasonality will be in the increase or stabilize in the current position.

In conclusion, seasonal variation in incidence of T1D in children with newly recognised diabetes supports the role of different environmental factors in diabetes onset. Most children were diagnosed with diabetes in autumn and winter. The youngest children aged 0-4 years showed less marked variation of the incidence of 
diabetes as compared to older subjects. Future analyses of environmental factors are needed to explain the causes of seasonality.

\section{Conflict of Interest}

Authors have no potential conflicts of interest. This is the retrospective analysis, for this type of study formal consent is not required.

\section{References}

[1] Watad A, Azrielant S, Bragazzi NL et al. Seasonality and autoimmune diseases: The contribution of the four seasons to the mosaic of autoimmunity. J Autoimmun 2017; 82: 13-30

[2] Krogvold L, Edwin B, Buanes T et al. Detection of a low-grade enteroviral infection in the islets of langerhans of living patients newly diagnosed with type 1 diabetes. Diabetes 2015; 64: 1682-1687

[3] Oikarinen S, Tauriainen S, Hober D et al. Virus antibody survey in different European populations indicates risk association between coxsackievirus B1 and type 1 diabetes. Diabetes 2014; 63: 655-662

[4] Laitinen OH, Honkanen H, Pakkanen O et al. Coxsackievirus B1 is associated with induction of $\beta$-cell autoimmunity that portends type 1 diabetes. Diabetes 2014; 63: 446-455

[5] Witek A, Wieczorek M. Virological and molecular methods in enteroviruses infections in 2004-2008, Poland. Przegl Epidemiol 2009; 63: $379-382$

[6] Rajtar B, Majek M, Polański Ł et al. Enteroviruses in water environment-a potential threat to public health. Ann Agric Environ Med 2008; 15: 199-203

[7] Durá-Travé T, Gallinas-Victoriano F. Seasonal variations in calcidiol and parathyroid hormone levels in healthy children and adolescents in Navarre, Spain: A cross-sectional study. JRSM Open 2016; 7: 2054270416632704

[8] Moltchanova EV, Schreier N, Lammi N et al. Seasonal variation of diagnosis of Type 1 diabetes mellitus in children worldwide. Diabet Med 2009; 26: 673-678

[9] Gerasimidi Vazeou A, Kordonouri O, Witsch M et al. Seasonality at the clinical onset of type 1 diabetes-Lessons from the SWEET database. Pediatr Diabetes. 2016; 17 (Suppl 23): 32-37

[10] Craig ME, Jefferies C, Dabelea D et al. International Society for Pediatric and Adolescent Diabetes. ISPAD Clinical Practice Consensus Guidelines. Definition, epidemiology, and classification of diabetes in children and adolescents. Pediatr Diabetes 2014; 15 (Suppl 20): 4-17

[11] Samuelsson U, Carstensen J, Löfman $O$ et al. Seasonal variation in the diagnosis of type 1 diabetes in south-east Sweden. Diabetes Res Clin Pract 2007; 76: 75-81

[12] Kalliora MI, Vazeou A, Delis D et al. Seasonal variation of type 1 diabetes mellitus diagnosis in Greek children. Hormones (Athens) 2011; 10: 67-71

[13] Spaans EA, van Dijk PR, Groenier KH et al. Seasonality of diagnosis of type 1 diabetes mellitus in the Netherlands (Young Dudes-2). J Pediatr Endocrinol Metab 2016; 29: 657-661

[14] Patterson CC, Gyürüs E, Rosenbauer J et al. Seasonal variation in month of diagnosis in children with type 1 diabetes registered in 23 European centers during 1989-2008: Little short-term influence of sunshine hours or average temperature. Pediatr Diabetes 2015; 16: 573-580
[15] Ardicli D, Kandemir N, Alikasifoglu A et al. Clinical characteristics of type 1 diabetes over a 40 year period in Turkey: Secular trend towards earlier age of onset. J Pediatr Endocrinol Metab 2014; 27: 635-641

[16] González RN, Torres-Avilés F, Carrasco PE et al. Association of the incidence of type 1 diabetes mellitus with environmental factors in Chile during the period 2000-2007]. Rev Med Chil 2013; 141: 595-601

[17] Peczyńska J, Peczyńska J, Jamiołkowska M et al. Epidemiology of diabetes type 1 in children aged 0-14 in Podlasie Province in years 2005-2012. Pediatr Endocrinol Diabetes Metab 2016; 22: 15-20

[18] Xin Y, Yang M, Chen XJ et al. Clinical features at the onset of childhood type 1 diabetes mellitus in Shenyang, China. J Paediatr Child Health 2010; 46: 171-175

[19] Kida K, Mimura G, Ito T et al. Incidence of Type 1 diabetes mellitus in children aged 0-14 in Japan, 1986-1990, including an analysis for seasonality of onset and month of birth: JDS study. The Data Committee for Childhood Diabetes of the Japan Diabetes Society (JDS). Diabet Med 2000; 17: 59-63

[20] Goday A, Castell C, Tresserras R et al. Incidence of type 1 (insulindependent) diabetes mellitus in Cataloniam, Spain. Diabetologia 1992; 35: 267-271

[21] Padaiga Z, Tuomileht J, Karvonen M et al. Seasonal variation in the incidence of type 1 diabetes mellitus during 1983 to 1992 in the countries around the Baltic sea. Diabet Med 1999; 16: 736-743

[22] Jackson C, Mangtani P, Hawker J et al. The effects of school closures on influenza outbreaks and pandemics: Systematic review of simulation studies. PloS One 2014; 9: e97297

[23] Vehik K, Lynch KF, Schatz DA et al. Reversion of $\beta$-Cell Autoimmunity changes risk of type 1 diabetes: TEDDY study. Diabetes Care 2016; 39: 1535-1542

[24] Samuelsson U, Lindblad B, Carlsson A et al. Residual beta cell function at diagnosis of type 1 diabetes in children and adolescents varies with gender and season. Diabetes Metab Res Rev 2013; 29: 85-89

[25] Waldhoer T, Schober E, Tuomilehto J. Long-term patterns in seasonality of insulin-dependent diabetes mellitus diagnosis in Austrian children. J Clin Epidemiol 1997; 50: 159-165

[26] Rosenbauer J, Herzig P, von Kries R et al. Temporal, seasonal, and geographical incidence patterns of type I diabetes mellitus in children under 5 years of age in Germany. Diabetologia 1999; 42: 1055-1059

[27] Karvonen M, Tuomilehto J, Virtala E et al. Seasonality in the clinical onset of insulin-dependent diabetes mellitus in Finnish children. Childhood Diabetes in Finland (DiMe) Study Group. Am J Epidemiol 1996; 143: 167-176

[28] Scott RS, Brown LJ, Darlow BA et al. Temporal variation in incidence of IDDM in Canterbury, New Zealand. Diabetes Care 1992; 15: 895-899

[29] Hyppönen E, Läärä E, Reunanen A et al. Intake of vitamin D and risk of type 1 diabetes: A birth-cohort study. Lancet 2001; 358: 1500-1503

[30] Eringsmark Regnéll S, Lernmark A. The environment and the origins of islet autoimmunity and type 1 diabetes. Diabet Med 2013; 30: 155-160

[31] Lewiński A, Skowrońska-Jóźwiak E. Calcium and vitamin D supply in polish population-facts and myths. Ann Agric Environ Med 2014; 21: 455-456 